\title{
BUPIVACAINE- CLONIDINE MIXTURE FOR EPIDURAL ANAESTHESIA
}

Anshul Jain, Chavi Sehgal,Veena Gupta, Roopesh Kumar

1. Lecturer, Department of Anaesthesiology, M. L. B. Medical College, Jhansi, Uttar Pradesh.

2. Lecturer, Department of Anaesthesiology, M. L. B. Medical College, Jhansi, Uttar Pradesh.

3. Professor, Department of Anaesthesiology, M. L. B. Medical College, Jhansi, Uttar Pradesh.

4. Assistant Professor, Department of Anaesthesiology, M. L. B. Medical College, Jhansi, Uttar Pradesh.

\section{CORRESPONDING AUTHOR}

Dr. Anshul Jain,

Lecturer, Department of Anaesthesiology,

M.L.B Medical College, Jhansi

Uttar Pradesh,

E-mail: dranshulrachna@rediffmail.com

Ph: 00919411685406.

ABSTRACT: BACKGROUND: "Epidural anaesthesia" the most versatile and suitable technique of central neural blockade as it provides excellent pain relief both intraoperatively and postoperatively. Clonidine is a a2 adrenoreceptor agonist. Traditionally, used as antihypertensive, but now uses based on sedative, anxiolytic and analgesic properties are increasing day by day. The goal of this study is to evaluate the analgesic property of epidural clonidine in two different doses of $1 \mathrm{ug} / \mathrm{kg}$ and $2 \mathrm{ug} / \mathrm{kg}$. MATERIAL AND METHODS: The present study was conducted in the department of Anaesthesiology M. L B Medical College Jhansi India. Subjects include 120 ASA status I and II patients of either sex, aged 21 years to 60 years, undergoing elective infraumbilical and lower limb surgery.

The subjects were randomly divided into three groups:

Group I Patient were given plain bupivacaine (0.5\%)

Group II Patient in this group were given $0.5 \%$ bupivacaine with clonidine in the dose of $1 \mathrm{mg} / \mathrm{kg}$ body weight.

Group III Patient in this group were given $0.5 \%$ bupivacaine with clonidine in the dose of $2 \mathrm{mg} / \mathrm{kg}$ body weight RESULTS: Latency of sensory block as judged by loss of pin prick sensation was $16.63 \pm 3.08,14.81 \pm 2.32,11.13 \pm 2.08 \mathrm{~min}$ in Group I, Group II and Group III respectively. Percentage of patient with Grade III blockade were $40 \%, 67.5 \%, 77 \%$ in in Group I, Group II and Group III respectively. Mean duration of analgesia was $2.8 \pm 0.43,4.7 \pm 0.56,5.1$ \pm 0.69 in Group I, Group II and Group III respectively. CONCLUSION: This can be concluded that epidural clonidine with bupivacaine shortens the onset of analgesia with good motor block, excellent haemodynamic stability and extended post-operative analgesia.

KEY WORDS: Epidural anaesthesia, Clonidine, Bupivacaine, Adjuvant

MESH TERMS: Clonidine, Bupivacaine, Anesthesia epidural

INTRODUCTION: The aim of modern anaesthesia is not only limited to diminish pain during surgery but to maintain this during postoperative period too. "Epidural anaesthesia" the most versatile and suitable technique of central neural blockade provides excellent pain relief both intraoperatively and postoperatively, with very low incidence of side effect.

The main limitation of local anaesthetics with epidural block is its slower onset of action and requirement of high dose. Here comes role of an adjuvant. These adjuvants when combined 
with local anaesthetics increase duration of block, improve quality of blockade and accelerate onset of block.

Epidural opiates and benzodiazepines are well known adjuvants. However they are associated with side effects viz. respiratory depression, vomiting etc.

The use of centrally administered $\alpha-2$ adrenergic agonist clonidine ${ }^{1}$ has recently been buoyed by the search for an effective alternative and/or adjunct to central opiate therapy because of the absence of the side effect (nausea vomiting, respiratory depression, pruritus, urinary retention) associated with that form of therapy. Clonidine when administered neuraxially as an adjuvant is associated with only mild hypotension and minimal reduction in heart rate.

Clonidine produces analgesia by interacting with alpha 2 adrenergic receptors. These receptors are located on superficial laminae of spinal cord and brain stem nuclei implicated in pain, so analgesia may be produced at peripheral, spinal and brain stem sites. ${ }^{2,3}$

The present study is being undertaken on the selective population of Bundelkhand, to assess the analgesic properties and dose response relationship of clonidine with Bupivacaine in epidural block in infraumbilical surgeries.

METHODS: After institutional ethical committee approval, 120 ASA status I and II patients of either sex, aged 21 to 60 years, undergoing elective infraumbilical and lower limb surgeries were included.

Thorough pre-anesthetic checkup of every patient was done. After which patient were subjected to routine and special investigations if required.

The procedure along with possible risks and complications were explained. The patients were divided into three groups randomly via computer generated group allocation as per serial number of patient:

1. Group IPatient were given plain bupivacaine $(0.5 \%)$ in the dose of $15-20 \mathrm{ml}$

2. Group II Patient were given bupivacaine $(0.5 \%) 15-20 \mathrm{ml}$ with clonidine in the dose of $1 \mu \mathrm{g} / \mathrm{kg}$ body weight.

3. Group III Patient were given bupivacaine $(0.5 \%) 15-20 \mathrm{ml}$ with clonidine in the dose of $2 \mu \mathrm{g} / \mathrm{kg}$ body weight

Observations were made by a third person and neither patient nor researcher knows the result until completion of the study.

Each patient received $10 \mathrm{mg}$ Diazepam orally a night before surgery. No sedative, narcotics drug were given pre, intra or postoperatively.

Each patient was re-examined thoroughly before application of epidural block. Pulse rate, blood pressure, Respiratory rate, $\mathrm{SpO}_{2}$ were recorded. Preoperative ECG was obtained using continuous monitoring device.

After establishing an intravenous access using 18G intravenous cannula, epidural puncture was done in L3-L4 interspace under full aseptic condition, by 18 Gauge Tuohy's needle. Epidural space is identified by loss of resistance technique using LOR syringe filled with saline. After 5 minutes of test dose local anaesthetic solution with or without clonidine was injected.

After application of epidural injection patient were assessed for:

ONSET OF ACTION: Assessed at 5, 10, 20 and 30 minutes after epidural injection. Loss of temperature sense was tested using cold saline in test tube. Loss of pain sensation was tested by pinprick. Motor block is tested by deep tendon reflex and by using Bromage scale ${ }^{4}$ and graded 
from I to IV. When there was no pain sensation, surgeon is allowed to proceed with the surgery.

Vitals were monitored at regular interval in whole perioperative period till 24 hours of surgery.

Post-operative analgesia was assessed by Verbal Analogue Scale ${ }^{5}$ which is calculated by analgesia on demand. The analgesia on demand was given and time noted. The total duration of analgesia was recorded.

Complications such as nausea, vomiting, drowsiness, respiratory depression, hypotension, retention of urine, pruritis and others were looked for, during the total period of observation, and were treated appropriately.

Patients were observed post operative period for 24 hours. The overall evaluation of technique was analyzed as excellent, good ,fair and poor in terms of patient acceptance.

All the observations were analyzed using SPSS statistical software and the results were compared (via paired $T$ test) to determine the ' $p$ ' value. A ' $p$ ' value of less than 0.5 was considered significant where as $p$ value $<0.01$ was considered highly significant.

RESULTS: Table 2 shows Group wise distribution of age, weight and duration of surgery there was no significant difference between each Group.

The onset of blockade (assessed by loss of temperature sense, touch, pin prick and vibration sense) of all the groups has been mentioned in table 3. Temperature sense was first to go in all the three groups followed by touch and pin prick respectively. As in many patients of Group I vibration sense was intact it was analyzed separately.

Table 3 When onset of block was compared statistically using 't' test, the difference was significant in Group I vs Group II and Group I vs Group III in all parameters. The difference was significant in Group II vs Group III between latency to loss of pin prick and latency to loss of pressure sense. Thus addition of clonidine in Group II in dose of $1 \mathrm{ug} / \mathrm{kg}$ reduces the latency period of all parameters by a significant degree. On further increasing the dose to $2 \mathrm{ug} / \mathrm{kg}$ the latency was not decreased in respect to touch and temperature, however latency to pin-prick sensation decreases significantly.

Table 4 shows measurement of motor block by Bromage Scale after 30 minutes. There is Grade IV block in 40\%, 67.5\%, 77\% of cases of Group I, Group II, Group III respectively. Thus clonidine enhances the motor block in a dose dependent manner.

Table 4 After 30 minutes of administration of epidural block vibration sense was assessed over medial malleolus by tuning fork. Table 5 shows the observations that in Group I only $45 \%$ have loss of vibration sense, this increases to $80 \%$ and $90 \%$ in Group II, Group III respectively.

Table 5 Mean duration of analgesia in the three groups has been shown in Table 6. Duration of analgesia is maximum in Group III i.e. 306 41.4 minutes and minimum in Group I i.e. $168 \pm 25.8$ minutes. When we compared statically the difference was significant between Group I and Group II ( $p$ value $<0.5$ ). The difference is highly significant ( $p$ value $<0.01$ ) between Group I and Group III.

Table 6 Observation of vital monitoring has been mentioned in Table 7. In Group I there is increase in pulse rate after the administration of epidural block intraoperatively $\left(89.96^{*} \pm\right.$ $8.13)$. The difference is significant in comparison to pre-operative value $(81.72 \pm 6.48)$. The pulse rate remains high in post-operative period also (94.23 \pm 5.87 ) which is significant in comparison to pre-operative value. In Group II there is statically insignificant change in pulse 
rate intra- operatively when compared to pre-operative value. However in post-operative period pulse rate increases significantly as compared to pre-operative value. In Group III there is highly significant reduction in pulse rate after administration of epidural block i.e. $80.04 \pm 6.12$ in pre-operative period and $73.12 \pm 4.89$ in intra-operative period. However pulse rate returns to baseline in post-operative period $(78.37 \pm 6.81)$ which is signified by the statistically insignificant difference between post-operative and pre-operative values. Mean BP was the the vital parameter observed and compared. In all the three groups there is reduction in mean blood pressure after administration of epidural block. The difference is significant in Group I and is highly significant in Group II and Group III.

Table 7 Postoperatively patients were asked to give their subjective opinion about the anaesthetic technique used in terms of 'excellent'; 'good'; 'fair' and 'poor'. Table 8 shows the results obtained in the three Groups. In Group I 27.5\% patients graded technique as fair. In Group II 18 patients (45\%) graded technique as good while in Group III 55\% of patient graded technique as good. Maximum number of patients reporting technique as excellent are in Group III (27.5\%). Table 8.

DISCUSSION: “Epidural anaesthesia” the most versatile and suitable technique of central neural blockade provides excellent pain relief both intraoperatively and postoperatively, with very low incidence of side effect. Constant search is going to improve the quality of the technique by adding number of adjuvants viz opioids, clonidine, neostigmine, ketamine.

The use of 0 ?adrenergic agonists in spinal and epidural space as adjuvant was set by Schmitt etal in 1974 who demonstrated profound analgesic activity of intracerebroventricularly administered 0 国国adrenergic agonist 6 .

Clonidine induce antinociception by activating the descending noradrenergic inhibitory system, by inhibiting synaptic transmission within the dorsal horn of the spinal cord via activation of spinal cholinergic neurons and by releasing epidural opioids 7 .

In the present study addition of clonidine in Group II in dose of 1ug reduces the latency period of all parameters of sensory block by a significant degree. On further increasing the dose to $2 \mathrm{ug} / \mathrm{kg}$ the latency was not decreased in respect to touch and temperature, however latency to pin-prick sensation decreases significantly.

The above findings are in accordance to the findings of Klimscha, W. et al (1995) who had also observed the early onset of blockade by addition of clonidine ${ }^{8}$. These findings can be explained by the fact that Clonidine acts synergistically with local anaesthetics because of its action of opening potassium channels 9 .

Addition of clonidine also increases the fraction of patient with loss of vibration sensation. Persistence of vibration and proprioception increase the anxiety of the patient as they can sense that something is happening over them though they do not feel pain. None of the literature published so far has documented vibration sense separately, loss of vibration sense increase the patient acceptability to the anaesthetic technique. This loss of vibration sense can be explained on the basis of synergistic effect of clonidine and local anaesthetic.

Degree of motor block was assessed by using Bromage Scale just prior to commencement of surgery. Addition of clonidine in the dose of $1 \mathrm{ug} / \mathrm{kg}$ improves the quality of motor blockade. Further increase in dose of Clonidine to $2 \mathrm{ug} / \mathrm{kg}$ increase the fraction of patient with Grade IV block to $77.5 \%$.

Level of block as assessed by pin prick method shows that majority of patient in all group have T7 , T8 block. Mean level of blockade in Group I and Group II was T8, while it was T7 
in Group III. The fraction of patient with T6 blockade was highest in patient Group III.

Post-operative analgesia was extended to 1.8 times as compared to control Group. This was also supported by Carabine UA etal ${ }^{\mathbf{1 0}}$ who used extradural clonidine and bupivacaine for postoperative analgesia. He had reported that postoperative analgesia of clonidine is a dose dependent phenomenon with a maximum effect after 75-100 ug.

Cardiovascular parameters i.e. pulse rate and blood pressure were well maintained without any ECG changes, throughout the peri-operative period. The initial response to stress which was very prominent in control Group was very transient when clonidine was used in doses of $2 \mathrm{ug} / \mathrm{Kg}$. However in the dose of $2 \mathrm{ug} / \mathrm{kg}$ there is significant decrease in the pulse rate, which resolves spontaneously within 6 hours post-operatively.

CONCLUSION: This can be concluded that epidural clonidine with bupivacaine shortens the onset of analgesia with good motor block, excellent haemodynamic stability and extended postoperative analgesia. Moreover addition of clonidine also improves the quality of blockade as evident by loss of vibration sense.

\section{REFERENCES:}

1. Nichols, A.J., J.P. Hieble and R.R. Ruffolo. The pharmacology of peripheral alpha 1- and alpha 2adrenoceptors. Rev Clin Basic Pharm. 1988 Jan-Dec;7(1-4):129-205

2. Millar J, O'Brien FE,Williams GV,Wood J. The effect of ionphoretic clonidine on neurons in the rat superficial dorsal horn. Pain 1993; 53:137-45

3. Kehlet H. "Post operative pain what is issue". Br J Anaesth 1994;72: 375-378

4. $\quad$ Bromage PR. Epidural analgesia. Philadelphia: WB Saunders, 1978:144.

5. Hartrick CT, Kovan JP, Shapiro S: The numeric rating scale for clinical pain measurement: a ratio measure? Pain Practice 2003, 3:310-316.

6. Schmitt H, Le Douarec JC, Petillot N. Antinociceptive effects of some alphasympathomimetic agents. Neuropharmacology. 1974 May;13(5):289-294.

7. Post C., Archer T., Minor B. G. Evidence for crosstolerance to the analgesic effects between morphine and selective $\alpha_{2}$-adrenoceptor agonists. J. Neural Transm. 1988;72:1-9

8. Klimscha W, Chiari A, Krafft P. Hemodynamic and analgesic effects of clonidine added repetitively to continuous epidural and spinal blocks. Anesth Analg 1995;80:322-7

9. Butterworth JF, Strichartz GR. The $\alpha 2$ adrenergic agonist clonidine and guanfacine produce tonic and phasic block of conduction in rat sciatic nerve fibers. Anesth Analg 1993; 76:295-301

10. Carabine UA, Milligan KR, Moore J. Extradural clonidine and bupivacaine for postoperative analgesia. Br J Anaesth. 1992;68:132-5 
Table-1 :

Bromage Scale

\begin{tabular}{|llll|}
\hline Grade & $\%$ & Degree of block & Criteria \\
\hline I & 0 & Nil & Free movement of thigh, legs and feet \\
\hline II & 33 & Partial & $\begin{array}{l}\text { Just able to move knees, with free } \\
\text { movement of feet }\end{array}$ \\
\hline III & 66 & Almost complete & $\begin{array}{l}\text { Unable to move knee with free movement } \\
\text { of feet }\end{array}$ \\
\hline IV & 100 & Complete & Unable to move legs or feet \\
\hline
\end{tabular}

Table 2

Table showing Groupwise mean age, weight and duration of surgery.

\begin{tabular}{|cccc|}
\hline Parameter & Group I & Group II & Group III \\
\hline Age(years) & $38.62 \pm 3.64$ & $37.57 \pm 2.30$ & $39.02 \pm 3.14$ \\
\hline Weight $(\mathrm{Kg})$ & $54.22 \pm 2.88$ & $53.2 \pm 2.93$ & $55.6 \pm 2.67$ \\
\hline $\begin{array}{c}\text { Duration of } \\
\text { surgery(min) }\end{array}$ & $82.69 \pm 12.31$ & $82.69 \pm 12.31$ & $82.69 \pm 12.31$ \\
\hline
\end{tabular}

Table 3 Table showing Latency of Sensory Block (minutes).

\begin{tabular}{|cccc|}
\hline Parameter & Group I & Group II & Group III \\
\hline $\begin{array}{c}\text { Temperature } \\
\text { (Mean } \pm \text { SD) }\end{array}$ & $6.28 \pm 2.31$ & $4.18 \pm 1.32$ & $3.87 \pm 1.91$ \\
\hline $\begin{array}{c}\text { Touch } \\
\text { (Mean } \pm \text { SD) }\end{array}$ & $11.22 \pm 2.84$ & $8.16 \pm 2.12$ & $7.73 \pm 1.86$ \\
\hline $\begin{array}{c}\text { Pinprick } \\
\text { (Mean } \pm \text { SD) }\end{array}$ & $16.63 \pm 3.08$ & $14.81 \pm 2.32$ & $11.13 \pm 2.08$ \\
\hline
\end{tabular}

Table 4: Groupwise distribution of Motor Blockade

(Mentioned in term of number of patients achieving Grade IV Bromage Scale in relation to time [in minutes] after administration of epidural block)

\begin{tabular}{|c|c|c|c|}
\hline Time & $10 \mathrm{~min}$ & $20 \mathrm{~min}$ & $30 \mathrm{~min}$ \\
\hline Group I & 4 & 12 & $16(40 \%)$ \\
\hline Group II & 8 & 17 & $27(67.5 \%)$ \\
\hline Group III & 9 & 19 & $30(77 \%)$ \\
\hline
\end{tabular}


Table 5: Groupwise distribution of Loss of vibration sense observed after 30 minutes

\begin{tabular}{|l|r|}
\hline Group I & $18(45 \%)$ \\
\hline Group II & $32(80 \%)$ \\
\hline Group III & $36(90 \%)$ \\
\hline
\end{tabular}

Table -6 Mean Duration of Analgesia

\begin{tabular}{|l|l|}
\hline Groups & $\begin{array}{l}\text { Mean Duration of analgesia } \pm \\
\text { SD (Minutes) }\end{array}$ \\
\hline Group I & $168 \pm 25.8$ \\
\hline Group II & $282 \pm 33.6$ \\
\hline Group III & $306 \pm 41.4$ \\
\hline
\end{tabular}

Table 7 Table showing pulse rate (per min), Mean B.P (mm of $\mathrm{Hg}$ ),

\begin{tabular}{|ccccc|}
\hline & Parameter & Pre-op & Intra-op & Post-op \\
\hline \multirow{3}{*}{ Group I } & \multirow{2}{*}{ Pulse Rate } & 81.72 & $89.93^{*}$ & $94.23^{*}$ \\
& & \pm 6.48 & \pm 8.98 & \pm 5.87 \\
\cline { 2 - 5 } & \multirow{2}{*}{ Mean BP } & 94.45 & $89.96^{*}$ & $102.45^{*}$ \\
& & \pm 9.09 & \pm 8.13 & \pm 11.02 \\
\hline \multirow{3}{*}{ Group II } & \multirow{2}{*}{ Pulse Rate } & 78.89 & 81.09 & $83.92^{*}$ \\
& & \pm 7.93 & \pm 6.71 & \pm 5.87 \\
\cline { 2 - 5 } & \multirow{2}{*}{ Mean BP } & 96.56 & $86.65^{* *}$ & 98.45 \\
& & \pm 8.71 & \pm 9.15 & \pm 10.11 \\
\hline \multirow{2}{*}{ Group III } & \multirow{2}{*}{ Pulse Rate } & 80.04 & $73.12^{* *}$ & $76.37^{* *}$ \\
& & \pm 6.12 & \pm 4.89 & \pm 6.81 \\
\cline { 2 - 5 } & \multirow{2}{*}{ Mean BP } & 97.27 & $82.89^{* * a}$ & 96.45 \\
& & \pm 8.89 & \pm 8.67 & \pm 9.09 \\
\hline
\end{tabular}

\footnotetext{
* Significant increase as compared to pre-operative value

** Significant decrease as compared to pre-operative value

**a Highly significant decrease as compared to pre-operative value
} 
Table 8 PATIENT ACCEPTANCE OF ANAESTHESIA TECHNIQUE IN EACH GROUP

\begin{tabular}{|c|c|c|c|c|c|c|}
\hline \multirow[t]{2}{*}{ Grade } & \multicolumn{2}{|c|}{ Group I } & \multicolumn{2}{|c|}{ Group II } & \multicolumn{2}{|c|}{ Group III } \\
\hline & No. & $\%$ & No. & $\%$ & No. & $\%$ \\
\hline Excellent & 4 & 10 & 9 & 22.5 & 11 & 27.5 \\
\hline Good & 5 & 12.5 & 18 & 45 & 22 & 55 \\
\hline Fair & 11 & 27.5 & 7 & 17.5 & 5 & 12.5 \\
\hline Poor & 20 & 50 & 6 & 15 & 2 & 5 \\
\hline
\end{tabular}

